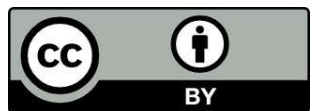

\title{
GEOGRAFIA DA RELIGIÃO, ESPAÇO SAGRADO E PENTECOSTALISMO: ANÁLISE DE UMA ESPACIALIDADE PENTECOSTAL
}

\author{
Geography of Religion, Sacred Space, and Pentecostalism: \\ Analysis of a Pentecostal spatiality
}

Clevisson Junior Pereira Doutorando do PPGGeografia - UFPR Bolsista CAPES-REUNI clevisson@ufpr.br

Sylvio Fausto Gil Filho Professor Associado do Departamento de Geografia Universidade Federal do Paraná - UFPR Bolsista Produtividade Fundação Araucária faustogil@ufpr.br

RESUMO: Partindo de uma base conceitual oriunda da Geografia da Religião, o presente trabalho busca entender algumas das possíveis relações entre o culto pentecostal e a categoria espaço sagrado. Enfatizando a experiência religiosa individual e de grupo, em relação à dinâmica espacial, fazemos um estudo de caso valendo-nos de um "culto de ceia" de uma pequena congregação das Assembleias de Deus; bem como de algumas bibliografias institucionais da referida denominação. Observando a dimensão ritualística/doutrinária, social e teológica que o culto pentecostal proporciona, procuramos depurar as articulações espaciais deste movimento carismático. Nosso objetivo principal foi ressaltar como o culto pode expressar diferentes espacialidades da experiência religiosa pentecostal; ao mesmo tempo aprofundando uma dinâmica interna (“espiritual”) e uma externa (comunal).

Palavras chave: Geografia da Religião, Espaço Sagrado, Pentecostalismo, Espacialidades, Experiência Religiosa.

\begin{abstract}
From a conceptual base from the Geography of Religion, the present work seeks to understand some of the possible relations between the Pentecostal worship service and the category sacred space. Emphasizing the individual and group religious experience, regarding spatial dynamic, we make a case study using a "Lord's Supper" worship service from a little congregation of the Assemblies of God; and using some institutional bibliographies from that denomination, too. Observing the ritualistic/doctrinal, social and theological dimensions that the Pentecostal worship service offers, we seek to depurate the spatial articulations of this charismatic movement. Our main goal was highlight how the worship service can express different spatialities of the Pentecostal religious experience; at same time deepening an internal dynamic ("spiritual") and an external dynamic (communal).

Keyword: Geography of Religion, Sacred Space, Pentecostalism, Espatialities, Religious Experience.
\end{abstract}




\section{Introdução}

A importância de estudar como determinado grupo religioso se expressa espacialmente e como entende/percebe o seu espaço se baseia no fato de que tais grupos compõem significativamente a dinâmica social. Esta por sua vez estrutura o espaço geográfico à medida que espacializa suas relações no ambiente.

Nesse sentido, para entender a dinâmica espacial que a sociedade impõe ao ambiente, é necessário compreender como os grupos religiosos apreendem e agem no seu espaço de ação - cultural, social, territorial, econômico, etc. Um passo fundamental para tal empreendimento é procurar entender, através da categoria espaço sagrado, a dinâmica das espacialidades religiosas; e por conseqüência apreender como se estrutura o espaço de ação de determinado grupo - visto que as espacialidades podem nos fornecer pistas de como a cosmovisão religiosa se articula à prática cotidiana dos fieis.

Tendo em vista que nas recentes décadas o Movimento Pentecostal ${ }^{1}$ atingiu mais de um século de atuação (COX, 2001) e que no Brasil tem se mostrado como o maior grupo religioso não-católico (LIMA; DIAS, 2009), entendemos que analisar uma reunião religiosa do referido movimento pode proporcionar bases para uma maior compreensão das dinâmicas do fato religioso.

Assim, nossa intenção aqui foi analisar uma prática pentecostal para entender sua sistemática espacial e nela captar as espacialidades que evidenciam modos distintos de atuação no ambiente. Nosso intento focou-se em uma comunidade religiosa pentecostal da Igreja Evangélica Assembleia de Deus em Curitiba - IEACD. Tal escolha se deu por dois motivos principais: primeiro, a referida denominação é uma das duas primeiras manifestações pentecostais que se estabeleceram no país, possuindo uma tradição centenária (CAMPOS JR, 1995; BARRERA, 2005); e segundo, é a maior denominação pentecostal do Brasil (LIMA; DIAS, 2009).

\footnotetext{
${ }^{1}$ Basicamente o Movimento Pentecostal surgiu como uma ramificação/dissidência do Protestantismo Histórico. Suas origens remontam Igrejas Cristãs não católicas que na virada do século XIX para o XX, principalmente em terras norte-americanas, começaram a adotar distintas práticas religiosas (CAMPOS, 2005); dentre tais práticas, um dos pontos de sustentação para o emergente movimento cristão era o "Batismo com o Espírito Santo" evidenciado pelo falar em outras línguas - glossolalia (fenômeno exercitado pelos pentecostais, que consiste na emissão de sons, indiscerníveis, através de um estado de êxtase religioso) (PASSOS, 2005).
} 
No intuito de cumprir nossa agência e captar a cosmovisão do grupo pentecostal $^{2}$, buscamos em duas fontes principais as bases para construir a presente reflexão: a) nos valemos de observações de um culto realizado pela comunidade religiosa. Frequentando o ambiente do Templo, a fim de participar da dinâmica litúrgica, buscamos captar em uma cerimônia de "Santa Ceia" alguns elementos que estruturam o ritual religioso; interpretando-os à luz de suas significações teológicas e sociais. E, b) nos valemos de uma breve pesquisa bibliográfica de alguns materiais da denominação escolhida. Pelo fato de procurarem disseminar suas doutrinas e pontos de vista a referida denominação possui uma Editora - A Casa Publicadora das Assembléias de Deus (CPAD) -, que está vinculada à Comissão Geral das Assembléias de Deus no Brasil, responsável pelas suas publicações institucionais. E são alguns de seus materiais ${ }^{3}$ que também analisamos para melhor compreensão do nosso estudo.

Com isso queremos além de desvelar um pouco mais da experiência pentecostal na dinâmica social, expor como a Geografia da Religião pode contribuir para o entendimento do fenômeno religioso em sua articulação comunal e pessoal.

Geografia da religião e análise do espaço sagrado

Várias ciências procuram dar sua contribuição, nos estudos da religião, pesquisando o campo da subjetividade religiosa; a fim de entender as diversas dimensões do fenômeno. A ciência geográfica, através de uma concepção mais cultural e humana, tem na Geografia da Religião sua área de pesquisa que se preocupa em analisar as variáveis que ligam o fenômeno religioso ao espaço geográfico.

\footnotetext{
2 Preferimos utilizar no de correr do trabalho o termo pentecostal, apesar de ser abrangente, ao invés do nome da denominação escolhida, porque a identidade pentecostal é uma forte característica apresentada pela bibliografia institucional e pelas declarações dos fiéis da congregação da Assembleia de Deus analisada; e também porque as práticas religiosas estudadas no presente são recorrentes em outras denominações do pentecostalismo.

${ }^{3}$ Foram utilizados no presente trabalho os seguintes materiais: uma Revista de Escola Dominical (edição comemorativa da CPAD) que enfatiza o centenário do movimento pentecostal e suas principais doutrinas e credos (CPAD, 2006); um livro da própria editora que conta a história das Assembleias de Deus no Brasil e suas principais convicções de fé (CPAD, 1982); e alguns livros de autores tradicionais das Assembléias de Deus no Brasil editados pela CPAD: como o de Menzies e Horton (2005) que aborda sobre as doutrinas e fundamentos da fé pentecostal; e o de Damião (2003) que fala sobre o impacto da religião na história da humanidade - destacando o papel do pentecostalismo. Também como complemento da nossa análise bibliográfica nos valemos de alguns fragmentos dos comentários de Donald C. Stemps (2002), comentarista da Bíblia de Estudo Pentecostal editado no Brasil pela CPAD.
} 
Pensando na profundidade imposta pelo fenômeno religioso, a abordagem geográfica não pode se restringir apenas às dinâmicas locacionais ou ritualísticas; mas, com um viés mais humanista, também deve explorar idéias além das análises geométricas e funcionais (GIL FILHO, 2001). O geógrafo escolhendo a espacialização do fenômeno religioso como objeto de pesquisa, deve ter em mente a dinamicidade do espaço sagrado. Assim, deve reconhecer a essência da experiência religiosa como uma estrutura estruturante do espaço (GIL FILHO, 2008).

A Geografia da Religião em boa parte de sua historiografia é caracterizada por um ciclo tese-antítese-síntese; em que a tese é mostrada como a religião sendo determinada pelo ambiente; a antítese sendo a influência da religião no mundo; e a síntese como a recíproca rede de relações entre religião e o ambiente (PARK, 2004; KONG, 1990). No século XX vemos essa área do conhecimento surgir a partir da Geografia Humana clássica como subdisciplina acadêmica; evidenciando a religião como produto da prática humana e resultado material (paisagem) da cultura religiosa (GIL FILHO, 2007; PARK, 1994).

A partir da segunda metade do século XX, anos 1960, 70 e 80, ocorre um florescimento de uma fenomenologia religiosa, sob o prisma humanista-cultural, evidenciando-se por parte de alguns geógrafos como Isaac, Büttner e Tuan uma preocupação com a natureza da experiência religiosa (KONG, 1990). Esse novo prisma, de uma geografia humanista-cultural, tornou-se um dos caminhos por onde a Geografia da Religião buscou entender outras lógicas que permeiam o fenômeno religioso.

Assim, vemos a Geografia da Religião se ocupando com o fenômeno religioso visto como espaço de relações objetivas e subjetivas consubstanciadas em formas simbólicas mediadas pela religião (GIL FILHO, 2007). Tais relações é que procuramos observar na presente análise; ao buscar na religião cristã pentecostal suas ligações entre o espaço sagrado e o culto religioso. Por excelência o tema de investigação da Geografia da Religião pode ser o estudo do fenômeno religioso através da categoria espaço sagrado; pois a partir dela várias dimensões do fenômeno religioso se evidenciam (GIL FILHO, 2007). 
O Espaço Sagrado e suas espacialidades

"O espaço sagrado é a imagem da experiência religiosa cotidiana assim como sua própria referência" (GIL FILHO, 2001).

Segundo uma ótica mais prática, o espaço sagrado pode ser o lugar de mediação entre a terra e o céu (ELIADE, 1992); mas não apenas o seu receptáculo, e sim também a fonte irradiadora da sacralização. Porém, por outro prisma podemos entender o espaço sagrado não como a cristalização do fenômeno (sagrado/religioso), mas como parte das possibilidades relacionais do mesmo (GIL FILHO, 2001).

Relativizando as ideias de Mircea Eliade temos que:

O espaço sagrado seria, (...), o mundo do 'sentido', do 'real' fundado ontologicamente pela manifestação do sagrado. Assim, o 'espaço sagrado' é primordial, corresponde ao primeiro ato que impregna de sentido a experiência do homem religioso e o contextualiza no mundo. (GIL FILHO, 1999, p.98)

Dessa forma o espaço sagrado está muito mais próximo de um espaço percebido sensivelmente do que concebido plenamente no intelecto; é mais fácil senti-lo do que concebê-lo racionalmente. O espaço sagrado nesta dimensão sensível revela sua estrutura temporal e espacial; sendo configurado por certas espacialidades que constroem as relações em seu meio (GIL FILHO, 2008).

O espaço sagrado, no âmbito de sua estruturação, pode ser formado por diversas espacialidades - que dinamizam as relações que acontecem em seu interior -; visto que a religião, mesmo sendo pensada como possuidora de uma essência única (OTTO, 2007), não se limita à sua realidade fenomênica, antes é plural nas suas expressões. Tais expressões podem ser concebidas como espacialidades, pois, são fenômenos que se espacializam; estruturando e conformando o espaço sagrado. A experiência religiosa por se apresentar em uma diversidade de relações possibilita várias espacialidades no plano físico/material: como discurso religioso, ritos e a própria religião institucionalizada.

Neste viés, o espaço sagrado congrega em seu meio diversos elementos religiosos em relação mútua. Ocorrem espacializações daquilo que não é de natureza espacial; configurando-o através de valores/sentidos. Dessa forma o espaço sagrado é estrutural, pois o homem religioso classifica qualitativamente o seu interior (GIL FILHO, 2008). Há no espaço sagrado uma articulação entre as diferentes 
espacialidades; entre as expressões concretas e as representações. Podendo o espaço sagrado transparecer nas suas várias formas-espacialidades, a mais nítida materialmente é quando se apresenta como palco das práticas religiosas.

Nisto tudo vemos que o espaço sagrado é algo intrínseco ao fenômeno religioso; pois está diretamente ligado à sua manifestação. Desta forma ele é temporal e espacial e também constituído por espacialidades da experiência religiosa. De igual forma, no sistema religioso alvo da presente reflexão, a experiência pentecostal também se revela espacialmente; seja nas manifestações físico-espirituais (como a glossolalia), seja no lugar onde ocorrem os cultos ou ainda em atitudes rituais. Partindo desse viés é que buscamos entender quais as ligações entre o culto evangélico pentecostal e a categoria espaço sagrado.

\section{O Pentecostalismo}

As conturbações sociais, políticas/nacionalistas e religiosas da Europa (séculos XVII e XVIII) proporcionaram condições favoráveis para o aparecimento de um avivalismo religioso. Quando levado a América do Norte, pelos imigrantes europeus, fez surgir muitos grupos com ideais de reavivamento religioso e distanciamento em relação ao "mundo".

É no meio desse contexto que surgem as bases para o pentecostalismo, no final do século XIX e início do XX, nas aragens norte-americanas; logo se espalhando pela Europa e outras regiões do mundo (DAMIÃO, 2003, p.440). Ao passo que o movimento crescia, tendia a institucionalização; tomando caminhos distintos nos países onde se instalava.

O Pentecostalismo surge evocando uma tendência "nova" no meio cristão; procurando resgatar "antigas" experiências da comunidade apostólica do primeiro século, clamou por uma espiritualidade mais profunda. Assim, imputando certo paralelismo entre as experiências atuais e suas tradições, procurou dar um novo tom ao Cristianismo. Dessa forma, ao mesmo tempo em que explorou uma nova ênfase doutrinária e litúrgica, também procurou conservar uma base religiosa fixa (PASSOS, 2005, p.17). Ou seja, foram experiências "novas e atuais", paradigmáticas para o cristianismo - como a glossolalia e os movimentos "místicos" do Espírito Santo 
(GUIMARÃES, 2005), que resgatam outras formas de experiência mais remotas (como as mencionadas no livro de Atos dos Apóstolos) ${ }^{4}$; que são tidas como as originais e de origem segura/divina. Assim, essa nova tendência seria um retorno às origens; visto que, pelo olhar pentecostal, o complexo da cristandade teria se afastado (ou rejeitado) essa experiência primeira (CPAD, 2006).

Desde seu início os pentecostais adotaram uma interpretação prioritariamente literal da Bíblia e uma prática marcada pelo que consideram ser experiência do "Espírito" - iniciada pelo batismo no Espírito Santo e confirmada pelo dom das línguas estranhas/ glossolalia (PASSOS, 2005). Com isso trouxeram uma nova ênfase na experiência religiosa para o meio protestante. Embora outros movimentos tenham surgido de caráter semelhante, são as experiências pentecostais que se tornam distintivas no Cristianismo (CPAD, 2006).

Origens do Pentecostalismo no Brasil

O Pentecostalismo aportou em terras brasileiras através de estrangeiros. Em 1910 o italiano Luigi Francescon, um presbiteriano que havia passado pelas igrejas pentecostais norte-americanas, trouxe para São Paulo alguns ideais da doutrina pentecostal; formando a primeira Igreja Pentecostal em solo brasileiro - a Congregação Cristã no Brasil (CAMPOS JR, 1995). No ano seguinte, foi a vez de dois missionários suecos - Daniel Berg e Gunnar Vingren, ambos de origem batista mas que também tiveram contato com as novas experiências pentecostais em igrejas estadunidenses, trazendo para o Norte do Brasil a visão pentecostal; fundando em 1911 a Assembleia de Deus $^{5}($ CPAD, 1992).

O Pentecostalismo no Brasil, no decorrer do século XX, foi caracterizado por fases $^{6}$ bem definidas, apesar de não ser um consenso absoluto entre os estudiosos do tema. As transformações sociais, políticas e culturais que o Brasil e o mundo passaram, levaram a formação de Igrejas com características bem distintas. Dependendo do

\footnotetext{
4 "de repente, veio do céu um som, como de um vento impetuoso, e encheu toda a casa onde estavam assentados. E apareceram, distribuídas entre eles, línguas, como de fogo, e pousou uma sobre cada um deles. Todos ficaram cheios do Espírito Santo e passaram a falar em outras línguas, segundo o Espírito lhes concedia que falassem" (Atos dos Apóstolos, 2:2-4).

${ }^{5}$ Embora nesta época o seu nome fosse "Missão Fé Apostólica"; em referência as Igrejas pentecostais norte-americanas (Apostolic Faith Gospel Mission).

6 Para maior aprofundamento sobre as fases do Pentecostalismo no Brasil ver: PASSOS (2005); CAMPOS (1996); e, FRESTON (1994).
} 
contexto em que se dá a formação de determinada denominação, traços específicos são evidenciados; o que, em parte, levou os estudiosos do pentecostalismo a classificá-lo em fases.

O Pentecostalismo, apesar de ser um fenômeno mundial, e no Brasil sofrer fortes influências norte-americanas, criou características próprias da cultura nacional:

Os pentecostais podem ser considerados brasileiros, porque se abrasileiraram. Aqui eles se refizeram em suas representações e práticas. Tecendo afinidades com nossas referências culturais e religiosas e nossas demandas sociais, criaram sistemas de crenças e organizações originais capazes de arrebanhar multidões de fiéis. (PASSOS, 2005, p.18)

Assembléia de Deus em Curitiba - o início de um pentecostalismo no Paraná

Após a chegada dos missionários suecos em terras brasileiras, na primeira década do século XX, rapidamente a doutrina pentecostal da Assembléia de Deus criou raízes e expandiu-se; não demorando em despontar na maioria das capitais. E, em menos de duas décadas (1929) estabelecia-se no Paraná a Igreja Evangélica Assembléia de Deus em Curitiba - IEADC (CPAD, 1982).

Crescendo vertiginosamente, a Assembléia de Deus ganhou espaço no meio cristão de Curitiba; se espalhando pela maioria dos bairros. Com uma tendência de organização fortemente hierárquica e uma dinâmica espacial-proselitista não centralizadora, típico das territorialidades pentecostais (MACHADO apud ROSENDAHL, 1995), na segunda metade do século XX já se fazia presente de norte a sul da capital; bem como em várias cidades do Estado (IEADC, 2009).

O Culto - uma espacialidade do espaço sagrado

As Igrejas Cristãs possuem diversos sistemas ritualísticos / acontecimentos religiosos. As expressões espaciais da experiência religiosa são muitas. Para aprofundar nossa reflexão, valemo-nos de uma reunião realizada por uma congregação ${ }^{7}$ da Igreja

\footnotetext{
${ }^{7}$ Congregação da Assembleia de Deus de Jardim São Carlos/IEADC - bairro Pinheirinho; comunidade que iniciou suas atividades nos anos de 1960 - em 65 com reuniões de oração e leitura da Bíblia; e em 69 fundada como Instituição com 5 membros. Até o ano de 2009, já haviam passados pela referida congregação mais de treze pastores-dirigentes; na mesma época contava com 120 membros e com aproximadamente 150 congregados.
} 
Assembléia de Deus em Curitiba; visando identificar a espacialidade do culto/prática pentecostal.

Teologicamente o termo "culto", do latim cultus ("veneração"), pode significar a mais elevada homenagem que se presta a uma divindade. Na maioria das vezes, tal designação é dada a reunião devocional do corpo comunal/integrante de determinada fé. Ou seja, é o lugar têmporo-espacial onde ocorrem e se materializam os procedimentos/práticas e as ideologias religiosas.

O EVENTO RELIGIOSO - Um olhar teológico, social e simbólico

O evento religioso que foi objeto de análise é na verdade um culto cerimonial. Ou seja, um ato que exige certa formalidade e procedimentos que vão além da liturgia normal de um culto.

A cerimônia em questão é denominada "Culto de Santa Ceia". Trata-se de um memorial, um ato solene que leva o crente a relembrar o âmago de sua fé (o sacrifício vicário de Jesus). É neste evento que os cristãos pentecostais acreditam cumprir a segunda ordenança ${ }^{8}$ que Cristo deixou para a igreja; anunciando "a morte do Senhor, até que venha"9(STEMPS, 2002).

O foco do referido evento para os fieis é realizar momentos de adoração a Deus. E isso através de um culto especial; nele, promover o ato simbólico de "cear". A "Ceia" foi a última refeição feita por Jesus, e os seus discípulos, antes da sua crucificação. Na cerimônia hodierna se faz um compartilhar de "pão" e "vinho", a fim de relembrar as palavras ditas pelo fundador, sua morte, sua ressurreição e seu retorno; e também, reafirmar a profissão de fé.

As interações na espacialidade do culto

$\mathrm{O}$ evento que aqui brevemente descrevemos teve início no fim da tarde de sábado - mês de março 2009 - por volta das 19h e estendeu-se até aproximadamente às 21h30. O culto, em si, começou com a maioria dos que estavam presentes, ajoelhados, levantando clamores e orações. Em poucos minutos, a oração foi interrompida, e logo

\footnotetext{
${ }^{8}$ A primeira seria o batismo em águas e a segunda o ato de "cear" (MENZIES; HORTON, 2005).

${ }^{9}$ Comentário feito por STEMPS (2002) sobre I Coríntios 11:23-32.
} 
começaram canções religiosas - a princípio somente música instrumental. Após uma pequena oração, feita por quem dirigia a reunião, iniciaram-se momentos de cânticos com uma banda (com vários instrumentos de sopro). Na seqüência, foi feita uma leitura bíblica e orações; e, novamente retornaram aos cânticos. Findo estes, iniciou-se um momento mais social, o pastor deu alguns avisos de caráter religioso (atividades em que a Igreja está envolvida); e, na seqüência, fez a apresentação de todos os visitantes. A partir de então, iniciou-se o cerimonial relativo à "Ceia". Em frente ao púlpito, havia uma mesa, com bandejas cheias de pequeninas taças com "vinho" (suco de uva); e, alguns pães. Após mais uma leitura bíblica, exposição do texto lido e orações (para consagrar o pão e o "vinho"), os alimentos foram distribuídos para os membros da igreja. Enquanto o pão e o "vinho" estavam sendo servidos, a igreja permanecia louvando a Deus com músicas. Tendo grande destaque os cânticos entoados por um coral misto que conseguiu conduzir, grande parte da congregação, ao êxtase “espiritual". Assim que esta parte da cerimônia terminou, o culto encaminhou-se para o fim. Findo a distribuição da "ceia", e passados alguns minutos, já com o clima mais "ameno" emocionalmente, o pastor dirigente, convoca a todos a se colocarem em pé; e, juntos fazem a oração final; agradecendo o bom andamento da reunião.

Desde o início da cerimônia a atmosfera que parece envolver o ambiente, conduz os presentes à uma espécie de contemplação das coisas sobrenaturais. Através das músicas, das citações das narrativas sagradas, dos momentos introspectivos, sempre há um tipo de convocação/apelo ao transcendental/mundo "espiritual". Aparentemente, há uma busca por um estado de alma, em que os sentidos se desprendam das coisas materiais e se conectem a uma outra dimensão.

Em todos os momentos do culto, os congregados, em voz alta na maioria das vezes, glorificam à Deus; e constantemente o clima emocional atinge tal ponto, que não é difícil ver pessoas chorando, e falando o que os pentecostais chamam "Línguas Estanhas".

INTERPRETAÇÕES - Profunda experiência religiosa e o culto pentecostal

No culto de "Santa Ceia" a busca pelos cristãos pentecostais de uma profunda experiência religiosa se dá tanto nas formas práticas/material como íntima/espiritual. Ou 
seja, o ritual/prática é feito, mas, é apenas uma parte do processo. O objetivo principal é estabelecer uma "relação íntima com o divino". E esta relação "divina" é uma realidade totalmente diferente do seu cotidiano. Pois, tem origem em uma dimensão diferente da sua: a dimensão "espiritual”. O que na maioria das vezes é algo de difícil apreensão; por se tratar de algo tão pessoal e intuitivo.

O foco do evento é a busca por um contato com o sobrenatural; que se exterioriza nos gestos, objetos, palavras e sons. A espacialidade do ritual é estruturada por uma interpretação específica do discurso fundador; a fim de garantir sacralidade ao ato. Esta interpretação fornece uma noção/lógica espacial criada pelas narrativas e praticada pelos fiéis; condiciona as ações dos mesmos tanto no momento do culto como fora dele. Torna-se nítido que essa experiência com o divino, fundada num discurso próprio, é o que dá sentido às ações dos fieis.

Por ser algo diferente, e distinto da lógica convencional, se torna difícil apreender objetivamente esta dinâmica religiosa; porém, seus reflexos tanto no sujeito quanto na paisagem podem ser vistos.

Assim, por mais que a experiência "transcendental/com o divino" não seja passível de uma explicação teórico-conceitual, os seus reflexos podem ser observáveis; e, "uma vez que não é racional, isto é, que não pode desenvolver-se por conceitos, não podemos indicar o que é a não ser observando a reação do sentimento particular que o seu contato em nós provoca" (OTTO apud MARCHI, 2005, p.40). Ou seja, seus efeitos de caráter emocional se tornam evidentes. Essa ideia, das reações da experiência com o divino, se torna ainda mais clara no culto pentecostal, pois os reflexos emocionais estão presentes desde o início da cerimônia; com a glossolalia, por exemplo.

Esta experiência religiosa, evidenciada no culto, articula um espaço sagrado; através do culto a experiência com o "divino" se expressa em espacialidades - tanto física, social como culturalmente. E é na imbricação das diferentes espacialidades que a dinâmica do fato religioso acontece.

A espacialização da experiência religiosa no culto pentecostal

O panorama sentimental produzido no culto, evocando uma dimensão sobrenatural, ao mesmo tempo em que cria uma atmosfera "espiritual" também 
espacializa as convicções religiosas. Ou seja, dá sentido religioso ao espaço, que antes era somente físico; mas que agora possui significações "metafísica/espirituais".

A ligação - tão almejada pelos pentecostais - entre o divino e o fiel que o experimenta é, desta forma, transferido para o espaço onde os ritos, as crenças, as instituições se materializam.

O local onde acontece a cerimônia representa, assim, parte de um espaço sagrado. Pois, é neste lugar que o poder transcendental interage com os fieis: o poder ilimitado do divino entra em contato com o poder limitado da criatura.

Sob o tom de um "transcendente-teológico", duas espacialidades se destacam na presente prática religiosa: a do discurso religioso e do sentimento religioso. A espacialidade do discurso assume caráter sagrado a partir do momento em que é remetido ao Discurso Fundador e legitimado pela Instituição normatizadora. O sentimento religioso evidencia-se, enquanto espacialidade, na atitude de fé (experiência pessoal) e também nas manifestações "espirituais" dos fiéis (ex. dons do Espírito).

Nesse sentido, o momento do culto é legitimado, enquanto espaço sagrado, pela instituição, pelo discurso fundador e pelo sentimento religioso; sendo desta forma uma espacialidade preponderante no "espaço sagrado pentecostal".

\section{Dimensão “espiritual” versus dimensão física}

Para os pentecostais, como para a maioria dos cristãos, toda a cerimônia de caráter religioso, não tem um fim em si mesmo; ela representa a busca de uma certa dimensão “espiritual”. E mais, esta dimensão é a que prevalece em detrimento da dimensão física. Na visão da maioria dos pentecostais, essa busca transcendental não está somente acessível nos momentos cerimoniais; mas em qualquer situação do cotidiano (CHO, 1980). Essa esfera transcendente da experiência religiosa é na maioria das vezes tida como a dimensão superior, a dimensão utópica, ideal.

É essa a dimensão que aparentemente toma conta do ambiente religioso durante o culto; e mais, a sensação que emerge é que tal dimensão influencia diretamente a consciência dos presentes. No evento é nítida a superioridade dada à dimensão "espiritual” (transcendente); pois, na cosmovisão do grupo religioso, seria ela que influenciaria, transferindo "poder", a dimensão física. Assim, em nosso estudo de caso, depois de consagrado o "pão" e o "vinho", esses alimentos passaram a carregar 
uma verdade/idéia que não é deste mundo; e sim do mundo "espiritual" - a natureza física com propriedades "espirituais". Porém, estes mesmos alimentos continuam a ser o que eram; menos para os fieis, pois para estes se tornam sagrados (ELIADE, 1992, p.18).

Isto tudo demonstra como a dimensão "transcendental" influi diretamente no espaço vivido/cotidiano. Há uma ênfase nas relações entre o aqui (cotidiano/dimensão física) e o além (transcendente/dimensão "espiritual"); e são nestas relações que os mundos/espacialidades do espaço sagrado podem vir a se constituir (SAHR, 2003).

A experiência pentecostal suscita várias espacialidades do fenômeno religioso; que por sua vez, dinamizam as relações sociais (comunidade religiosa) e transcendentais (na interação com o sagrado-divino). Tal experiência legitima a classificação do lugar e reforça a consciência do grupo - fortalecendo sua representação. Assim, a cosmovisão peculiar que estrutura as relações sociais, espaciais e culturais do grupo pentecostal, a cada culto é reafirmada; principalmente em cerimônias como a "Santa Ceia".

Considerações Finais

$\mathrm{O}$ apelo transcendental que o fenômeno religioso traz nos faz rever abordagens filosóficas e incluir a possibilidade da existência do trans-humano, do não-racional ou do subconsciente. Pois, além da evidência social que a mais íntima experiência religiosa pode impor, existe também uma realidade subjetiva intrínseca à lógica religiosa, que apesar de diferente, se apresenta como base imprescindível do real - mesmo que esta seja apenas verdade para quem a vive: o fiel, o devoto. Deste modo, seja qual for o contexto espaço-temporal do fiel (homo religiosus), ele crê firmemente que existe uma realidade absoluta (divina/sagrada) que vai além deste mundo, transcendendo-o; porém tal realidade, aqui (nesse mundo) se manifesta; qualificando a sua existência e tornandoo real (ELIADE, 1992).

Assim, para uma melhor aproximação do significado do fenômeno religioso, é preciso considerar o aspecto não racional (OTTO, 2007), ou transcendental, que liga a vivência comum a um outro mundo; ao mundo das narrativas sagradas (religiosas); ao mundo supra-humano. 
Por mais que existam níveis do fenômeno religioso que não consigamos apreender conceitualmente, isso não deve significar uma desistência de nossa parte em pesquisá-lo. A dinâmica das dimensões de tal fenômeno estrutura os pensamentos e ações dos fiéis; condicionando a sua produção e atuação no espaço. Cabe-nos verificar as evidências que a religião demonstra no cotidiano; e nelas apreender a realidade. Nesse sentido é que buscamos, ao longo deste trabalho, estudar a experiência religiosa pentecostal; não em si mesma, mas nas suas múltiplas conseqüências - espacialidades.

$\mathrm{O}$ ato religioso analisado por nos fazer refletir sobre as dimensões que conhecemos, e ao mesmo tempo sobre as que desconhecemos, traz um sentimento de limitação racional. Pois, apesar de podermos observar e descrever ritos, cultos, ou qualquer que seja a manifestação religiosa, dificilmente conseguiremos explicar todos os fenômenos envolvidos. Isto se justifica, de uma forma aceitável, se considerarmos que possivelmente um transcendental (uma dimensão não apenas física) existe e interage com o meio físico. Mas isto, longe de ser algo limitador, pode ser um importante ponto de partida para futuras explorações.

Apesar de o evento analisado ser apenas um de muitos outros atos religiosos, ele revela o quão profundo pode ser o envolvimento dos fiéis com a sua crença. Onde tanto sujeito, matéria e espaço ganham significações que fogem a lógica tradicional.

\section{Referenciais}

BARRERA, P. Matrizes Protestantes do Pentecostalismo. In.: PASSOS, J. D. (org.). Movimentos do espírito: matrizes, afinidades e territórios pentecostais. São Paulo: Paulinas, 2005.

CAMPOS, L. S. Protestantismo y Pentecostalismo en el Brasil: Promesas de câmbios. In.: GUTIÉRREZ, B. F. (ed.). La Fuerza del Espírito: los Pentecostales em América Latina - um desafio a las iglesias históricas. Guatemala: AIPRAL-CELEP, 1996.

As origens norte-americanas do pentecostalismo brasileiro: observações sobre uma relação ainda pouco avaliada. Revista USP, São Paulo, n.67, p.100-115, 2005.

CAMPOS JR., L. C. Pentecostalismo: sentidos da palavra divina. São Paulo: Editora Ática, 1995.

CHO, D. P. Y. A Quarta Dimensão. São Paulo: Editora Vida, 1980.

COX, H. Fire From Heaven: The rise of pentecostal spirituality and the reshaping of religion in the twenty-first century. Cambrigde: Da Capo Press, 2001.

CPAD, Casa Publicadora das Assembleias de Deus. História das Assembleias de Deus no Brasil. $2^{\text {a }}$ Ed. Rio de Janeiro: CPAD, 1982. 
As Doutrinas Bíblicas Pentecostais: Centenário do Movimento Pentecostal Mundial (1906-2006). Lições Bíblicas, $3^{\circ}$ Trimestre de 2006.

DAMIÃO, V. História das Religiões: sua influência na formação da humanidade. Rio de Janeiro: CPAD, 2003.

ELIADE, M. O Sagrado e o Profano. São Paulo: Martins Fontes, 1992.

FRESTON, P. Breve história do pentecostalismo brasileiro. In.: ANTONIAZZI, A. et al. Nem anjos nem demônios: interpretações sociológicas do pentecostalismo. Petrópolis, RJ: Vozes, 1994.

GIL FILHO, S. F. Espaço de Representação e Territorialidade do Sagrado: notas para uma teoria do fato religioso. RA'E GÁ, Curitiba: Editora UFPR, n. 3, p.91-120, 1999. 78, 2001.

Por uma Geografia do Sagrado. RA'E GÁ, Curitiba: Editora UFPR, n. 5, p. 67-

Geografia da Religião: reconstruções teóricas sob o idealismo crítico. In.:

KOZEL, S. et al (orgs.). Da percepção e Cognição à Representação: Reconstruções teóricas da Geografia Cultural e Humanista. São Paulo: Terceira Imagem; Curitiba: NEER, 2007.

p.15.

Espaço Sagrado: estudos em geografia da religião. Curitiba: Ibpex, 2008,

GUIMARÃES, R. F. Os últimos dias: os pentecostais e o imaginário do fim dos tempos. REVER - Revista de Estudos da Religião, nº1, p. 31-53, 2005.

IEADC, Igreja Evangélica Assembleia de Deus em Curitiba. IEADC 80 anos: Jubileu de Carvalho 1929-2009 - Agenda 2009. Curitiba, 2009.

KONG, L. Geography and Religion: Trends and Prospects. Progress in Human Geography, v. 14, n 3, London, p. 355-371, 1990.

LIMA, F. R. F.; DIAS, A. C. Geografia da Religião no Brasil: censos demográficos e transformações recentes. Mercator, Revista de Geografia da UFC, ano 8, n.16, p.111124, 2009.

MARCHI, E. O sagrado e a religiosidade: vivências e mutualidades. História: Questões e Debates - O espaço do sagrado no século XXI. Curitiba, PR: Ed. da UFPR, ano 22, n. 43, p.33-53, 2005.

MENZIES, W. W.; HORTON, S. M. Doutrinas Bíblicas: Os Fundamentos da Nossa Fé. Rio de Janeiro: CPAD, 2005.

OTTO, R. O sagrado: aspectos irracionais na noção do divino e sua relação com o racional. São Leopoldo: Sinodal/EST; Petrópolis: Vozes, 2007.

PARK, C. Religion and Geography. Chapter 17. In: HINNELLS, J. (ed.). Routledge Companion to the Study of Religion. London: Routledge, 2004.

Routledge, 1994.

Sacred Worlds: an introduction to geography and religion. London:

PASSOS, J. D. Pentecostais: origens e começo. São Paulo: Paulinas, 2005. 
ROSENDAHL, Z. Geografia e Religião: uma proposta. Espaço e Cultura, UERJ, RJ, n 1, p.45-74, 1995.

O Sagrado e o Espaço. In.: CASTRO, I. E. et al (orgs.). Explorações Geográficas: percursos no fim do Século. Rio de Janeiro: Bertrand Brasil, 1997.

SAHR, W. D. Three worlds between Here and Beyond: Postmodern reflections on a geography of religion. [Trois mondes entre l'ici-bas er l'au-delà. Réflexions postmodernes sur la géographie de la religion]. Geographie et cultures, Paris, v. 47, p. 45-66, 2003.

STEMPS, D. C. Comentários sobre I Coríntios 11:23-32. Bíblia de Estudo Pentecostal. Rio de Janeiro: CPAD, 2002.

Recebido:22/10/2012

Received: $10 / 22 / 2012$

Aprovado: 28/11/2012

Approved: 11/28/2012 